\title{
Emancipatory Indigenous social innovation: Shifting power through culture and technology
}

\author{
Ella Henry, ${ }^{*}$ Jamie Newth** and Chellie Spiller**
}

\begin{abstract}
This paper explores the emancipatory impulse of Indigenous social innovation and social enterprise. Indigenous approaches to solving social disparities reflect a perpetual search for innovative ways to change the circumstances of Māori. Power is an understudied dimension of social innovation and social enterprise. This paper explores the power dynamics that structure the disadvantage and marginalisation that cause populations to be underserved by markets and that limit their access to resources. We highlight that it is not power per se that enables social change: rather, it is power shifts. Through a single, richly contextualised case study of a well-known Māori social innovator, Dr Lance O'Sullivan, we reveal and illustrate the nuances of Indigenous entrepreneurship in the Far North of Aotearoa New Zealand. The case epitomises the transformative impact a social entrepreneur can have on the provision of healthcare amid market and policy failures.
\end{abstract}

Keywords: social entrepreneurship, entrepreneurship, technology and innovation, cultural dimensions

Received 12 June 2017. Accepted 31 October 2017

\section{INTRODUCTION}

Ocial innovation is an emergent conceptual frame for understanding the creation of new initiatives $\checkmark$ to address systemic social and environmental issues. For researchers, policymakers, and practitioners across a range of organisational contexts, the promise of new (often hybrid) organisational logics, institutional arrangements, or public service modalities represents a compelling agenda for social change. Although the explosion of social innovation in the public narrative and its increased presence in policy agendas globally is relatively recent, many aspects of what we now call social innovation are not new (cf. Ayob, Teasdale, \& Fagan, 2016). Of particular note are the organisational and institutional practices of Indigenous populations, for which there is a significant gap in the social innovation and social entrepreneurship literature.

This article begins to address that gap through the analysis of a contemporary case study of a Māori social innovator, his innovative enterprise model, and how the opportunity, idea development and execution strategy emerged from the cultural, geographic, and socio-economic context in which he is embedded. We draw on the practices of Dr Lance O'Sullivan, medical doctor and social innovator in the Far North of Aotearoa New Zealand, to explicate the interplay between cultural capital and social innovation in a context of market failure and structured disadvantage.

* Te Ara Poutama, Auckland University of Technology, Auckland, New Zealand

** Department of Management and International Business, University of Auckland Business School, Auckland, New Zealand

Corresponding author: c.spiller@auckland.ac.nz 
First we outline the theoretical background of social innovation as a response to the structured nature of systemic market failure. This includes the consideration of the principal aim of social innovation as changes to power relations for the improvement of human capabilities (Nicholls \& Ziegler, 2015; von Jacobi, Edmiston, \& Ziegler, 2017). We then relate this literature to that of Indigenous enterprise to establish a more closely integrated theoretical backdrop. After presenting the case study of O'Sullivan and the initiative Manawa Ora, Korokoro Ora (iMOKO) innovation, we discuss how the innovation addresses specific social problems as they pertain to primary healthcare provision and how this alters social power dynamics.

\section{THEORETICAL BACKGROUND}

\section{Social innovation and social change}

Contemporary understandings of social innovation as a concept hold as defining features new forms of social relationships that generate new ideas for new solutions, with those solutions having a positive societal impact (Ayob, Teasdale, \& Fagan, 2016). Pol and Ville (2009) argue that a number of contested and contestable definitions of social innovation, while illustrative of the activities scholars are seeking to understand, are frequently too vague for empirical validation. These definitions range across innovations that seek institutional change (Heiskala, 2007), are for social purposes (Mulgan et al., 2007), for the public good, or address market failure (OECD, 2000).

The definition adopted for this article sees social innovation as 'the development and delivery of new ideas and solutions (products, services, models, markets, processes) at different socio-structural levels that intentionally seek to change power relations and improve human capabilities, as well as the processes via which these solutions are carried out' (Nicholls \& Ziegler, 2015: 2). This frame is useful because it encompasses the multiple forms of endeavour - social enterprise, social finance, social and Indigenous entrepreneurship - that occur across multiple levels - micro, meso, macro - that comprise this confused and contested space. The focus on power relations also centralises the position that for social innovations to generate systemic social change, as the discourse frequently suggests, then those innovations must disrupt the social dynamics that form the basis of the social problem in the first place (Nicholls, 2017). This definition also allows for theoretical integration of the means and ends of Indigenous entrepreneurship and its concomitant policies and institutions. Furthermore, this perspective holds normative value in that it prescribes what social innovation should achieve, and calls out those which seek to deploy social innovation policy to achieve outcomes within existing policy agendas rather that achieving fundamental changes to social structuration (Nicholls, 2017; von Jacobi, Edmiston, \& Ziegler, 2017). This builds on and provides greater instructive clarity than Heiskala's conception of social innovation as 'changes in the cultural, normative or regulative structures of the society which enhance its collective power resources and improve its economic and social performance' (2007: 59).

In this structural understanding of social innovation, social enterprise sits as a nested micro-paradigm where the logics and modalities of trading for social purpose is positioned as ideational derivatives of meso-level norms of welfare economics that sit within the broader political-economic paradigm in which policy approaches to the use of market-based approaches to social welfare are established (Nicholls \& Teasdale, 2017). Moreover, this institutionalist perspective highlights the contextualised and inherently political nature of enterprise that seeks to create social change. In the simplest terms, social and Indigenous enterprise, as a form of social innovation that seeks to create a solution to a market failure will inevitably alter extant power relations between stakeholders (Newth \& Woods, 2014).

In tracing the development of the social innovation literature, Ayob, Teasdale, and Fagan (2016) attempted to clarify the dynamic interplay between innovations, social relations, and societal impact 
by classifying contemporary scholarly contributions into types, based on their central definitional themes - 'social relations', 'societal impact', and 'technological innovation'. This approach demonstrates that not only has social innovation scholarship dramatically increased over the last 20 years, but also conceptualisations of it are dominated by the innovator's intent to utilise and/or achieve changes in social relations to ultimately achieve positive societal impact. Ayob, Teasdale, and Fagan's (2016: 649) model of how social innovation leads to social change indicates the two frames through which this is understood in the literature: the utilitarian approach, whereby an innovation delivers change through 'aggregate individual utility'; and a more radical perspective, in which the innovation drives change through 'new forms of power relations'. It is this more radical perspective that this article explicates through its application to an emergent Indigenous social innovator and the emancipatory impact of his innovation. Moreover, the shifting of power relations' perspective of social innovation (MacCallum, Moulaert, Hillier, \& Haddock, 2009; Moulaert, 2009; Moulaert, MacCallum, Mehmood, Hamdouch, Hillier, \& Beinstein, 2010) most appropriately speaks to the drivers of Indigenous entrepreneurs and their emancipatory potential.

To date the concept of power has received limited attention in the social innovation and entrepreneurship literature, despite related fields focussed on human action for social change, such as social movement theory, drawing their instrumentality from this basis (cf. Alvord, Brown, \& Letts, 2004). Following the theoretical underpinnings, and the lead, of the Creating Economic Space for Social Innovation (CrESSI) project, we likewise draw on Mann's (1986) framework of power (cf. Heiskala, 2015). Mann (2013: 1) contends that power is 'the ability to get others to do things they otherwise would not do' and has ideological, economic, political, and military sources. For Mann (2013: 1, italics added)

Ideological power derives from the human need to find ultimate meaning in life, to share norms and values, and to participate in aesthetic and ritual practices with others ... economic power derives from the human need to extract, transform, distribute, and consume the produce of nature ... military power [is] the social organization of concentrated and lethal violence ... political power is the centralized and territorial regulation of social life.

This is important for understanding the role of social innovation in achieving social change as these sources of power, and their dynamic interplay, determine the relative agency of individuals, communities, and populations. These dynamics also structure the disadvantage and marginalisation that cause these populations to be underserved by markets and/or prevent access to resources (von Jacobi, Edmiston, \& Ziegler, 2017). Furthermore, power relations and societal structures are inherently resistant to change, particularly when coupled with the entrenched interests of powerful actors, thereby setting the very agenda of the 'social' in social innovation as a particularly challenging form of innovation (Newth \& Woods, 2014). We therefore posit that the intent of social innovation is to alter these structured power relations as the central driver of social problems and inhibiter of the development of human capabilities.

Marginalisation is a general frame for understanding the structured exclusion of populations. While not a complete catch-all for all social problems on which social innovators focus their attention, it does speak to the systemic reason(s) why certain populations are excluded from the benefits of social and economic progress:

To be marginalised is to be unimportant, to lack power, to remain unheard by society and divorced from its decision-making processes and institutions ... marginalised people or marginalised groups are those who are at the margins of society with respect to valuable opportunities, resources, etc. From an evaluative perspective, therefore, marginalisation requires an account of the good or goods, whose lack is associated with some relevant marginalisation. It focuses on ethical disadvantage (Wolff \& De-Shalit 2007), where disadvantage refers to a lack of human capabilities. (von Jacobi, Edmiston, \& Ziegler, 2017: 150) 
This frame also compels social innovation researchers and practitioners to consider how innovations actually shift the dynamics that create and reinforce social problems, how they therefore enhance human capabilities, and the importance of increasing the agency of those whom the innovation is purporting to benefit, such that they can use that agency to pursue the opportunities that they themselves value.

Amartya Sen's (1985) capabilities approach has proven to be a powerful framework in a number of scholarly fields for understanding marginalisation, poverty, and disadvantage. It is particularly valuable for theoretical development here because it helps to explicate not only the purpose and power of social innovation in terms of its ends and its means (von Jacobi, Edmiston, \& Ziegler, 2017) but also the emancipatory nature of Indigenous entrepreneurship and the methodological stance of much Indigenous research. The capabilities approach emphasises the heterogeneity of ends, to achieve which different people will apply their differing abilities and resources. Central to Sen's discourse, therefore, is the importance of individual agency to pursue and realise opportunities; that which deprivation and marginalisation so often inhibits. This has stood in contrast to the economic orthodoxy that has privileged the access and utility of commodities as the indicator of well-being to the exclusion of other variables. In particular, Sen (1985):

...believes that ultimately, what is important is not so much a matter of having but rather what one is capable of being or doing (capabilities) and actually being or doing (functionings). For instance, having a computer is different from being capable of using it to generate happiness through, say, surfing the Internet for information, which is again different from actually using the computer in such a fashion to generate happiness (Yujuico, 2008: 500).

This wider social innovation literature provides a theoretical backdrop for an Indigenous change agent who is responding in practical and pragmatic ways to address health disparities in his community. However, in many ways this literature does not adequately address the Indigenous context from which the problem and opportunity emerged, a gap which some scholars are beginning to address (cf. Anderson, Honig, \& Peredo, 2006; Overall, Tapsell, \& Woods, 2010; Tapsell \& Woods, 2010; Newth \& Woods, 2014). Therefore, to understand the phenomenon under investigation, it is necessary to draw on the literature of Indigenous enterprise.

\section{Indigenous entrepreneurship}

There are -370 million Indigenous people, across 70 countries worldwide. It is recognised that Indigenous peoples practise traditions unique to their cultures, and that they retain social, cultural, economic, and political characteristics, which make them distinct from the majority cultures in lands that have been colonised. Histories of Indigenous peoples have highlighted the negative impacts of those majority cultures, most notably through conquest and colonisation. The ability of Indigenous peoples to survive and flourish, despite these impacts, often rests on the enterprises they create to achieve their goals for social change and social justice.

Indigenous entrepreneurship is a foundation for understanding Indigenous enterprise, for it is often Indigenous entrepreneurs that create and operate such entities. Indigenous entrepreneurship has been defined as, 'the creation, management, and development of new ventures by Indigenous people for the benefit of Indigenous people. The organisations thus created can pertain to either the private, public or non-profit sectors' (Hindle \& Moroz, 2010: 363). Hindle and Moroz developed a framework for Indigenous entrepreneurship research that highlights the relative importance of communities rather than individuals, and which emphasises culture and social norms over resources and profits.

Peredo, Anderson, Gailbraith, Honig, and Dana (2004) acknowledge that Indigenous peoples strive to plan and control their own development, their rights over resources, and to rebuild their communities. However, Indigenous development founded on Indigenous culture and society has proved 
problematic, as Indigenous entities struggle to exist in the economic and organisational systems of the dominant culture. In a similar vein, Peredo and McLean (2010) discuss how Indigenous peoples around the world have turned to entrepreneurial endeavour to improve the conditions of themselves and their communities. They suggest that 'Indigenous communities act collectively as both entrepreneur and enterprise, with profit-making subordinate to social outcomes' (2010: 614).

For Cahn, 'In Indigenous societies throughout the world "business" and economic activities are embedded in cultural and social aspects, creating unique styles of entrepreneurship, which are often community-oriented, and with diverse livelihood outcomes' (2008: 1). Her focus is Indigenous entrepreneurship, culture and micro-enterprise in Samoa. Cahn found that, 'where micro-enterprises blend well with fa'aSamoa ${ }^{1}$, an "Indigenous" style of enterprise develops, and fa'aSamoa is a motivating factor and asset, which enhances entrepreneurial activity' (2008: 16). Further, she found that whilst cash was an important outcome of enterprise, so too was the social and cultural capital, 'that was developed through actively engaging in the values and expression of fa'aSamoa' (2008: 17).

In their definitive text Dana and Anderson note that, 'there is a rich heterogeneity among Indigenous peoples, and some of their cultural values are often incompatible with the basic assumptions of mainstream theories. Indigenous entrepreneurship often has non-economic explanatory variables... We propose that entrepreneurship opportunity recognition and evaluation is therefore culturally determined: however, we note that culturally determined opportunities for entrepreneurship are often disrupted by entities external to Indigenous peoples' (2007: 601).

Further, Henry, Dana, and Murphy (2017: 5) argue that Indigenous entrepreneurship differs from the dominant theoretic themes of mainstream research into entrepreneurship, which tends to focus on the characteristics of individuals. The literature from Indigenous scholars, on the other hand, often focusses on the emancipatory nature of entrepreneurial actions and intent. They write, 'The approach is different because it focusses on how entrepreneurs and communities can surmount unique social and environmental constraints that apply to them'.

Herein lies one of the conceptual overlaps between social innovation, cultural capital, and Indigenous entrepreneurship. Aramburu and Saenz (2011) note that an organisation's ability to innovate is linked to its intellectual capital, or new knowledge. This paper argues that an organisation's innovation capabilities are also linked to its cultural capital, which Throsby defines as 'an asset embodying cultural value' (1999: 3). Throsby adds that culture should be added to the three traditionally acknowledged forms of capital - physical, human, and natural - because it enriches economic analyses. The Indigenous entrepreneurship literature also highlights the significance of both social and cultural capital. Light and Dana (2013) recognise that social capital assists Indigenous entrepreneurs in terms of the social, networking and others resources it brings and the strategic relationships it generates, whilst Henry, Dana, and Murphy (2017) link cultural capital to environmental context, personal identity and self-efficacy, which have been found to enhance entrepreneurial intent amongst Indigenous peoples.

\section{Māori enterprise}

The Māori of Aotearoa New Zealand are part of the Polynesian diaspora, who have traversed and populated the Pacific for over 3,000 years. Traditional Māori society was tribal, and kinship-based, founded on a political economy that Mauss (1954) describes as one of gift-exchange and reciprocity. The ancient cosmological beliefs of the Māori honoured kinship, spirituality and guardianship, values that exemplified the connectivity between all living things, and ancestral linkages to the pantheon of gods (Hēnare, 2001).

1 Fa'aSamoa literally means 'the Samoan way', the socio-political and cultural life of Samoan people. 
After discovering Aotearoa New Zealand, Māori lived in relative isolation from those outside the South Pacific until the first recorded arrivals by Abel Tasman in 1642 and James Cook in 1769. These newcomers brought animals and artefacts unknown to the Māori, including pigs, chickens, nails, and axes. These treasures provided a strong incentive to maintain good relations with the pale-skinned visitors. Wilson (2012) states, 'From the 1790s, Māori produced pork and potatoes for this trade', particularly the increasing number of whaling and sealing vessels which plundered the South Pacific. By the 1830s, Māori owned ships, delivering manufactured goods such as kauri tree spars, tree-nails, treated flax (for rope), and potatoes and pigs throughout the Pacific. Producing goods for trade coincided with the traditional value of hospitality and giftexchange (Mauss, 1954). Petrie notes, 'The rapid expansion of Māori commerce was not simply chance, but had been advanced by deliberate strategies in line with customary practice' (2006: 40). According to Petrie (2006), in 183028 ships made 56 voyages carrying Māori produce between New Zealand and Sydney.

Thus, Māori embraced innovation and enterprise, which may have influenced many in the early years of engagement with settler society to maintain good relations with the British, and Britons to maintain positive relationships with Māori through trade and the introduction of Christianity. In 1840, Governor Hobson arrived to promote a Treaty with Māori, guaranteeing the protection of New Zealand as a formal British colony. After days of consultation amongst the tribes gathered at the settlement of Waitangi, the Treaty was signed on 6 February 1840. The Treaty of Waitangi is acknowledged as the founding document of New Zealand. Māori have perceived a lack of respect for its meaning and intent by successive New Zealand governments, leading eventually to open conflict in the Land Wars of the 19th century, protest and activism in the 20th century, and the emergence of an emboldened and 'embourgoised' Māori leadership in the 21st century. Operating in a Western economy, which the British instituted after 1840 and which New Zealand now embodies, Māori seek ways to engage in enterprise that reflects and protects Māori culture, values, and people.

Ameliorating the entrenched poverty and disadvantage of Māori, exacerbated by the longterm impacts of colonisation through the expropriation of land, language, culture and economic foundations, is a driving aspiration for a new generation of Māori leaders and innovators. Building enterprise that reflects Māori culture and philosophy, underpinned by the cultural capital of an entrepreneurial history, and the social capital of a united and tribal society with strong networks and cohesive connections, has become the challenge for this new generation of Māori entrepreneurs (Spiller, Pio, Erakovic, \& Hēnare, 2011; Foley \& O'Connor, 2013; Henry, Dana, \& Murphy, 2017).

\section{METHODOLOGY}

This study is Kaupapa Māori Research (Smith, 1998), which has been described as a research methodology, and a paradigm or philosophical worldview that incorporates ontological, epistemological, and methodological standpoints that shape the researcher's thinking about being, knowledge and knowledge-creation. For Henry and Pene (2001), Kaupapa Māori has evolved in the face of Eurocentric constructions of knowledge and consequent 'epistemic violence', which Seuffert notes has, 'claimed universal applicability across disciplines, cultures and historical periods' (1997: 98). The methodological principles shaping Kaupapa Māori Research, as method, have been articulated as:

- Being for, with and by Māori

- Validating Māori language and culture 
- Empowering Māori people

- Delivering positive outcomes for Māori.

(Henry \& Wikaire, 2013: 1)

The case study has been built from a combination of qualitatively-informed secondary sources comprised of news articles about Dr. Lance O'Sullivan and his own book The Good Doctor (2015). The case study also reflects informal and impromptu conversations with O'Sullivan and notes from attendance at several of his public talks and conference presentations. Dr. O'Sullivan also kindly agreed to review the case study and for this we are honoured and grateful.

Our data, then, come from three key sources: commentary by Dr O'Sullivan at various fora, in which one of the researchers was a participatory observer and took field notes; O'Sullivan's selfreported experiences as described in his autobiographical book; and publicly available texts. The latter were predominantly interviews conducted by journalists and therefore have the advantage of containing verbatim quotes by Dr O'Sullivan. Silverman points out that texts provide 'rich, naturally occurring, accessible data which have real effect in the world' (2006: 195).

Following Bowen's (2009: 29) exhortation apropos using documents as data, we provide 'detailed information about how the study was designed and conducted' in the following. In response to the call for papers for this special issue our first step was to identify potential case studies that warranted close academic inspection of Indigenous entrepreneurship. Taking a purposive sampling approach (Patton, 2002), we identified iMOKO as a suitable candidate, given what each us knew of Dr O'Sullivan and his efforts, which have been broadcast widely in the media, and through our own experiences of meeting him and hearing him talk.

We then gathered and scrutinised data sources and drafted the case study. Iterating between ourselves, we each evaluated the case text and explored emergent themes. Each researcher was assigned areas of entrepreneurship literature to examine. We brought our insights together and, after extensive discussion that centred on the case study and the trajectories of academic theorising relevant to our study, we iterated towards the present body of work. The anonymous academic review process, which provided valuable recommendations, also helped us in our endeavours.

Thus, our research design and analytical process resonates with Bowen's (2009: 27) description of using textual analysis as 'a systematic procedure for reviewing or evaluating documents'. He suggests that 'like other analytical methods in qualitative research, document analysis requires that data be examined and interpreted in order to elicit meaning, gain understanding, and develop empirical knowledge'.

There are a number of advantages to using extant documents as data. One advantage is that they are exempt from researcher intervention (Bowen, 2009) and do not rely on 'self-reported' data, which can be 'influenced by the subject's view of what the researcher might want to hear' (Harris, 2001: 191). To some extent, our data did contain a degree of self-reporting by Dr O'Sullivan in response to journalistic enquiry and his own organising of text in his book. However, our data were not moulded by self-report in response to our research agenda. As Bowen highlights, data distortion when using extant documents is generally not deemed an issue in terms of researcher impact on the construction of meaning and interpretation. A third advantage that has bearing upon this present study is that secondary data 'forces the researcher to think more closely about the theoretical aims and substantive issues of the study' (Hakim 1982: 16 in Harris, 2001) and this was our experience.

There are some disadvantages to using documents as data, although we do emphasise we did not entirely rely on documents but also availed ourselves of live presentations and talks given by Dr O'Sullivan, which gave us triangulation along with our iterative literature review process. According to Bowen (2009) one disadvantage is that documents are not produced for research purposes and 
might therefore not provide researchers with the detail they need to answer their research questions. However, as we were working inductively this study is akin to a grounded theory approach in its use of data (cf. Glaser \& Strauss, 1967).

Turning to case study as a method, this single case is best described as illustrative (Yin, 1994, 1984/2013) insofar as it elucidates Indigenous social entrepreneurship through the experience of a well-recognised exemplar. However, it is also revelatory (Yin, 1994, 1984/2013) as, when combined with our scholarly enquiry into power, the case yields much more depth and insight than mere illustration would reveal. As each of the authors is Māori, we are also concerned with the emancipatory dimensions of our research. In this undertaking we can be understood as adopting an 'Indigenous Standpoint' (Foley, 2004) wherein central concerns include surfacing unequal power relations in society and providing tangible benefit to Māori communities (Bishop, 1996, 2008; Smith, 1998). We were also committed to delivering a rich, insightful story (Dyer \& Wilkins, 1991) wherein narratives, as Heil and Whittaker (2007: 369) note, 'are a powerful means to shaping peoples thinking and actions' and 'have the capacity to alter the world we find ourselves in, in the most fundamental ways' (2007: 382). Kaye (1996: xix) believes that stories endure for a long time in part 'because they become closely identified with the culture of the system where they are heard and told'.

We align ourselves with Indigenous scholarship that views storytelling, in this paper through a single illustrative and revelatory case study, as a powerful medium to engage the community and transmit knowledge (Spiller \& Wolfgramm, 2015). Storytelling helps bring people continuously into relationship.

\section{CASE STUDY: iMOKO INNOVATION}

\section{Context}

The population of Northland (of which the Far North is a part) is estimated at 148,470, with $29 \%$ identifying as Māori. The Māori population in Northland is significantly younger than the non-Māori (36\% are aged less than 15 years, compared with $23 \%$ of non-Māori) and experiences high levels of socio-economic deprivation, unemployment and one-parent families, compared with the total New Zealand population (Robin, Mills, Tuck, \& Lennon, 2013).

In their review of rural communities' access to healthcare, Panelli, Gallagher, \& Kearns (2006) highlighted a number of barriers including distance to services, availability, time, and costs associated with travel to get healthcare, and oftentimes navigating difficult terrain. They also note financial barriers such as service costs, low income, and lack of access to insurance. Furthermore, social and economic factors, such as gender, age, ethnicity, and poverty, affect health service experience. Salient to our discussion is 'the increasing awareness of the complexity and interconnection of health issues that are embedded within broader conditions and constraints' (Panelli, Gallagher, \& Kearns, 2006: 1,105) wherein social, cultural, economic, and physical settings shape the health context.

According to Robin et al. (2013), poverty-related diseases are endemic in Northland. Acute rheumatic fever (ARF), for example, can result in structural damage to heart valves or rheumatic heart disease and is a significant cause of premature death and significant morbidity worldwide. ARF is preventable and its elimination is linked to problems with poor housing conditions including overcrowding, poverty, inequitable primary care access, and lack of awareness about the disease amongst those afflicted (Robin et al., 2013). Notwithstanding ARF is rare in most developed countries, rates of ARF in Northland have been historically amongst the highest in New Zealand, and disproportionately impact Māori children. In a study of ARF between 2002 and 2011 Robin et al. (2013) found that $95 \%$ of 108 ARF cases were Māori. Notably, the researchers detected the highest rates and largest disparity, with $94 \%$ of cases being Māori, in the 5-14 age group. Of these cases $60 \%$ were male and 
$40 \%$ were female. Ages of sufferers ranged from 4 to 26 years, with a mean age of 11.4 years. More than half (55\%) of ARF cases were in the most deprived - decile 10 - areas as measured by educational decile. Decile ratings use household measures such as income, proportion of parents on a benefit, occupation, education, and household crowding (Ministry of Education, 2017).

Thus, as Robin et al. (2013) highlight, ARF rates in Northland Māori aged 5 to 14 years are similar to those seen in developing countries and nearly double the rate of Auckland. Furthermore, and alarmingly, over the last 5 years Northland's ARF rates show an upward trend.

\section{iMOKO}

Lance O'Sullivan and his wife Tracey are the forces behind an innovative, disruptive virtual health service, iMOKO, which is part of a public health initiative Manawa Ora, Korokoro Ora. The virtual service, iMOKO, gets schools using smart devices to log unwell student's symptoms for diagnosis and prescription remotely. Navilluso Medical Ltd, the holding company of iMOKO, employs 21 doctors, nurses, health promoters, and community health workers. In 2015 the company won the inaugural business development fund grant of $\$ 30,000$ from Top Energy. The money was used to develop the remote diagnosis and treatment facility for rural communities across Northland and beyond (Scoop, 2015).

The iMOKO virtual health service covers schools from Northland to South Auckland, and currently captures 3,800 students. The change gave the O'Sullivan's the opportunity to promote health in a very different way. 'There are many barriers to healthcare - socio-economic, cultural, geographic', O'Sullivan says, 'with innovation and leadership we are doing our best to find ways of overcoming them' (NZ Herald, 2015).

\section{Solutions in response to market failure}

'There's a storm coming with disruptive health technology', says O'Sullivan. 'Airbnb, Alibaba and Uber are all examples of disruptive technology that change the way we live our lives'. He believes that a problem with the current health system is that it is 'incredibly risk-averse, so it can take years before enough evidence is gathered to support updating it - by which time, things have changed. With disruptive technology, we can help people now' (Goodall, 2016, emphasis in original).

\section{Shifting power through increasing agency of the marginalised}

O'Sullivan gives a personal experience (O’Sullivan, 2017) to explain how iMOKO works to drive innovation and change through new forms of power relations. He shows a photo of two young boys on a bike. 'See this boy here?' asks O'Sullivan, pointing to the one on the left, 'this boy saw the "Moko Foundation" on the van I was driving when visiting the remote Kare Kare Peninsula and called out to me, "Hey do you know Whaea?" I replied that indeed I did know Whaea. The boy, excited, described how he had a nasty skin infection which Whaea, a teacher's aide, had noticed at school one day. She had taken a photo and uploaded it to the iMOKO cloud. Within minutes a prescription was sent to Whaea and the young man received much needed drugs to clear up his condition'. O'Sullivan says what he loved the most about this encounter, was not that he, O'Sullivan, was cool, but that the heroine in this young man's life was Whaea. A woman who 'sees children every day at school and is empowered to do something about health problems'.

iMOKO staff visit schools in Northland on a regular basis to detect illnesses such as strep throat, which as noted is a major precursor for problems such as ARF for Māori children in Northland, and is linked to poverty. A cause of these high rates of disease is the overcrowded, damp, cold homes. 
'It's poverty, basically. I worked out I don't need to be a doctor to treat these people; I need to be a social worker' (Espiner, 2014). School staff are instructed on how to identify problems and send pictures of ailments such as skin infections via the internet, where they are diagnosed and scripts issued for treatment from the iMOKO base in Kaitaia. Records of those diagnoses and prescriptions are then referred to the child's own doctor.

Problems such as skin conditions have been reducing over time at schools where the programme operates. Children and their families have benefitted from the information they received about prevention of infections. The O'Sullivan's are also looking at expanding the programme to include throat swabbing as a means of identifying the potential for rheumatic fever before it becomes a serious health problem.

O'Sullivan wants to grow the programme well beyond the physical locale of Northland, and even New Zealand. 'We believe this model of care could create the opportunity to have a telemedicine clinic based in Kaitaia serving the needs of the country, and even further abroad ... There is no reason why Kaitaia could not become the Silicon Valley of New Zealand tele-healthcare' (NZ Herald, 2016).

\section{Disrupting structural, social and power dynamics}

The O'Sullivan's have faced numerous barriers on their journey to democratising healthcare. For example, their Te Kohanga Whakaora medical clinic, which they sold in 2016, caused outrage for treating sick people who could not afford to pay the full fee, charging them a small portion of what they would have to pay elsewhere. They had an emergency prescription fund, built on donations, for parents who cannot pay for medication. Other healthcare providers, Māori ones included, believed their business model was undermined by the O'Sullivan's principle of providing subsidised, even free, healthcare. A reporter, waiting for his plane at the small airport in Kaitaia, the town where the O'Sullivan's live, described how two Pākehā locals vented about O’Sullivan: 'bloody socialist', one said, 'keeps trying to give things away for free'. The other appeared convinced that 'Māori are trying to take over the hospital'. Both were aggrieved that Māori are getting special treatment (Espiner, 2014).

\section{Powered by cultural capital and an emancipatory impulse}

O'Sullivan is no stranger to marginalisation. His background and experiences have established an historical, social, and cultural platform that motivates him. Abandoned by his Māori father, O'Sullivan was raised by his Australian mother, the family dependent on a benefit. 'Alcohol shaped his life, made him violent and incapable of being a good husband and father. In turn, his life shaped my own', says O'Sullivan (NZ Herald, 2015). He describes the moment, two days before his father died:

I looked at my dad not as a man who was bitter and nasty. I looked at him as a man who was the product of his upbringing. And the effect of colonisation. He was one of 18 kids, they starved, they witnessed beatings, they were subjected to beatings. The beatings were the product of being absolutely dispossessed. So that allowed me to look at him not as a perpetrator of harm and hurt but rather a victim. But it took 35 years. (NZ Herald, 2015)

\section{Linking innovation with intellectual capital}

Expelled from two schools, labelled as a miscreant, O’Sullivan's rocky beginning set the stage for the journey of 'conscientisation' (cf. Smith, 1997) as a Māori. Going to Hato Petera College, in Northcote, Auckland, revealed his cultural heritage in a powerful, transformative way. Hato Petera College was established in 1928 to teach young Māori men Catholic and Māori values. The school was the first place, O'Sullivan observes, where he had been surrounded by positive Māori men: 'It was "Hey, your culture isn't skin-thick. Your culture is flowing through your veins and you just have to learn about it"' 
says O'Sullivan (NZ Herald, 2015). 'To be honest, it was probably what I'd been searching for my whole life'. He became a Dad at 20 and it wasn't until his twenties that he traced his whakapapa, his genealogy, to Ngapuhi, Tainui, Te Rarawa, Ngati Hau and Ngati Maru. O’Sullivan went on to study medicine after his second enrolment attempt, and was on the unemployment benefit after failing to receive important financial support.

Nowadays he receives numerous accolades and has received an array of glittering awards: In 2013 he was noted as an emerging leader by the Sir Peter Blake Trust, as a public health champion by the Public Health Association and as Māori of the Year. In 2014 he was voted the Kiwibank New Zealander of the Year and the Reader's Digest second-most-trusted New Zealander. In 2017 he was a finalist in the High Tech awards (NZ Herald, 2015). However, although he has accomplished great things, he never forgets what he is in service of: delivering healthcare to society's most poor, vulnerable, and marginalised.

\section{DISCUSSION}

Although set in a developed and prosperous nation, the case study describes a sub-context in which belonging to a particular ethnic group in a particular geographic context means that for many the benefits of the economic prosperity of that nation are not realised. Moreover, the case speaks not only to the economic disadvantage of that population and the negative health outcomes this generates but also to the failings of the mainstream health system for that population. In simple terms, the context of the case is Far North Māori in Aotearoa New Zealand being marginalised economically and underserved in the provision of healthcare through both market and policy failures.

Although those failures occur at the macro-level, our unit of analysis, the iMOKO innovation, represents a micro-level response to them. As an embedded actor with understanding of the problematic nature of healthcare provision in his community, that is barriers between the Māori community and standard healthcare provision modality, O'Sullivan developed social innovations as a member of the community he seeks to empower. This aligns with the tenets of the capability approach when applied to social innovation because the change in power relations and access to healthcare is developed from within the community by a member rather than applied to it by a central authority. It is therefore emancipatory in its impact on human capabilities - both means and ends - and the innovation and change are systemic and scalable.

From an Indigenous enterprise perspective, the case is illustrative of a social innovator's ability to combine cultural capital (also the animating force for O'Sullivan's action) with intellectual and financial capital in innovative ways to provide care that is accessible and appropriate to those that are underserved, with potential for even further impact on mainstream healthcare provision. The case reinforces the importance of cultural context and embeddedness for social innovation to be a manifestation of a society's desire for systems that work for it. However, like innovation generally, whilst grounded in culture and place, this social innovation is not constrained by these factors. For example, O'Sullivan has a vision that spans boundaries; his approach could be described as 'By Māori for Māori and the World', because, while iMOKO is inspired by and designed to meet the needs of a particular marginalised community, it can ultimately bring its benefits, and disruption, to the mainstream also (Christensen, 2013). O'Sullivan's success as an Indigenous entrepreneur accords with Mika's (2015, 2016) observation of people who harness indigeneity in inspirational, innovative ways to contribute to the well-being of the collective.

The case is revelatory of the politics that must imbue true attempts at social innovation, as it does any activity that seeks to shift power relations in society. The iMOKO innovation, an entrepreneurial endeavour to solve deeply entrenched health disparities by addressing the market failure in healthcare for Far North Māori, shifts the power of access to healthcare further into the hands of parents, 
caregivers, and the broader community. By empowering the community in this way, it weakens the power of the centrally determined status quo to shape the standardised provision of community health services. Although their causes are neither malicious nor the result of intentionally ineffective practices, the prevalence of easily treated 'diseases of poverty' speaks to a systemic failure in the provision of healthcare, alongside other economic and social variables, for this particular community.

The resistance of the status quo is in part overcome through O'Sullivan's use of cultural capital. In an Indigenous enterprise context, cultural capital is a key resource and the ability to deploy it is a vital factor in the implementation of social innovations. Innovations created by embedded actors enable the 'bottom-up' empowerment necessary to alter dominant power structures and contrast with 'top-down' policy regimes that remain ineffective or reify existing power dynamics. The case study therefore reveals the inherently political nature of enterprise that seeks social change, wherein exclusion and disadvantage are underpinned by social power dynamics. Social innovation is thus linked to social change through disruption of those dynamics.

The case study also highlights poverty and healthcare inefficacy as endemic social problems intertwined with culture and history and not just contemporary economic and welfare policy. Thus, it shows that power exists through time and space, that historical, social, and cultural contexts shape both problems and opportunities (Newth \& Woods, 2014). The case is illustrative of a strong emancipatory impulse, oriented to the common good, in Māori enterprise and innovation. This emancipatory impulse can be described as a cultural trait for Māori, historically and presently (Petrie, 2006; Spiller, Erakovic, Hēnare, \& Pio, 2010; Henry, 2012). This intersection of social innovation and Māori enterprise is yet to receive adequate scholarly attention. This case in particular demonstrates how social innovation is not about using power to drive social change per se. Rather it is the shift in power that drives social change that endures and that delivers on the promise of 'systemic social change' that is so often associated with social innovation.

\section{Linking social innovation to social change}

Table 1 outlines how the iMOKO innovation seeks to address three overlapping problematic aspects of healthcare provision for Māori in the Far North of Aotearoa New Zealand through altering the power dynamics that cause their marginalisation from healthcare. The first challenge is that general practitioner healthcare is primarily bound to a particular place - a doctor's office or clinic. Although to many this model seems normal and reasonable, it clearly still creates a challenge to get their children to a particular place at a particular time. It also reduces the availability of a particular doctor or clinic to a confined geographic region. For the general public this is not a widespread challenge. However, as the case study demonstrates, for some marginal communities that challenge can often be the difference between receiving or not receiving care. The iMOKO innovation of being able to connect the patient with a doctor via an app removes this challenge and increases the agency of those targeted. While the reduction in economic power of the healthcare orthodoxy is minimal, this small increase in economic empowerment for the target community by eliminating the costs of travel has the potential to enhance social welfare, through health outcomes, in powerful ways.

The second, closely related, challenge that the innovation seeks to address is the dominant Western modality for healthcare provision, which has underserved, if not disenfranchised, Māori in Northland. Many Māori in the region appear to be reluctant to make use of doctors until health situations become critical. Critics might argue the combination of formal clinical settings, non-Māori health practitioners, and long-distance travel to the nearest clinics contribute to this problem. When compounded with misunderstandings and a lack of education on health issues, this resistance presents a little understood but serious risk to community health. By enabling community members such as family members and teachers to facilitate the care of children in the community the cultural norms of collectivism in care for 
TABle 1. LinKING iMOKO social inNOVATIONS to potential SOCIAL CHANGE

\begin{tabular}{|c|c|c|c|}
\hline Social Problem & $\begin{array}{l}\text { Lack of access due to place: Access } \\
\text { to GP consultation is problematic } \\
\text { due to economic challenges of } \\
\text { formal clinic visits. Diagnosis not } \\
\text { made, treatment such as } \\
\text { medication not accessed }\end{array}$ & $\begin{array}{l}\text { Lack of access due to mode of } \\
\text { delivery: Cultural resistance to } \\
\text { formal consultation from a } \\
\text { typically non-Māori doctor in } \\
\text { clinical setting }\end{array}$ & $\begin{array}{l}\text { Lack of access due to business } \\
\text { model: A general socio-economic } \\
\text { issue is the dependence on a 'pay } \\
\text { for time' model of doctor access, } \\
\text { regardless of simplicity/ } \\
\text { complexity of diagnosis, thereby } \\
\text { reducing the aggregate doctor } \\
\text { time available and increasing } \\
\text { costs }\end{array}$ \\
\hline $\begin{array}{l}\text { Change via } \\
\text { innovation }\end{array}$ & $\begin{array}{l}\text { Diagnosis via app reduces barriers } \\
\text { to care (diagnosis) by removing } \\
\text { need for formal consultation. GP } \\
\text { care made affordable and } \\
\text { accessible }\end{array}$ & $\begin{array}{l}\text { Diagnosis and care is distributed } \\
\text { into community - schools, marae, } \\
\text { etc. - empowering a broader } \\
\text { range of community caregivers } \\
\text { such as teachers to connect } \\
\text { children to doctors }\end{array}$ & $\begin{array}{l}\text { Diagnosis of simple conditions can } \\
\text { be done very quickly and } \\
\text { remotely, and potentially be } \\
\text { automated. More doctors } \\
\text { become available via this channel } \\
\text { to more patients and simple } \\
\text { diagnoses are made more } \\
\text { efficiently, freeing up face- } \\
\text { to-face visits for more } \\
\text { challenging diagnoses }\end{array}$ \\
\hline $\begin{array}{l}\text { Change in power } \\
\text { dynamics for } \\
\text { target population } \\
\text { in healthcare }\end{array}$ & $\begin{array}{l}\text { Economic: Decrease in reliance on } \\
\text { financial resources to access } \\
\text { healthcare. Supplemented by } \\
\text { technology and community } \\
\text { processes }\end{array}$ & $\begin{array}{l}\text { Ideological: Increases power of } \\
\text { shared norms and values of } \\
\text { Indigenous communities of } \\
\text { collective care for children. } \\
\text { Decreases the negative impact of a } \\
\text { lack of understanding of } \\
\text { healthcare and resistance to } \\
\text { using non-Māori doctors }\end{array}$ & $\begin{array}{l}\text { Political: The centralised model of } \\
\text { GP care with subsidisation based } \\
\text { on visits loses its normative } \\
\text { power as care is delivered via an } \\
\text { alternative channel. } \\
\text { Economic: Some potential } \\
\text { disruption of the GP healthcare } \\
\text { market with diagnoses being } \\
\text { provided by any participating } \\
\text { doctor regardless of their } \\
\text { location }\end{array}$ \\
\hline
\end{tabular}

Note. GP = general practitioner.

children are leveraged into greater access to medical expertise. This power shift, in the terms of Mann (2013) is ideological. With the iMOKO innovation, the cultural basis of the target population's practices does not limit its ability to receive healthcare. In fact they enhance it as the community, acting on a more collectivist basis, has an increased power to get care to those who need it.

The third challenge to healthcare access is the standard business model through which general practitioner care is provided. The dominant paradigm of care via formal consultation for a fee (whether subsidised or not) applies regardless of whether that consultation is necessary or not. This reduces the efficiency of the deployment of a doctor's ability and power to prescribe treatment, referral, or advice. While this is not unique to a particular target community, when combined with the challenges of access due to 'place', it does reduce the total availability of medical expertise to the public, with marginal communities invariably being disproportionately disadvantaged. $\mathrm{MOKO}$ alleviates this challenge by enabling doctors to diagnose simple conditions and mobilise the appropriate resources without the need for a formal consultation. This reduces the geographic limitations of care and makes for a more fluid market for the supply of primary care. Not only does this confer greater power on community members who struggle to access care for economic reasons, but it also lessens the political power of centrally created systems that are not proving effective care for the marginalised.

\section{CONCLUSION}

This paper has highlighted a specific example of Indigenous social innovation and social enterprise as a means to explore and analyse the enduring nature of Indigenous approaches to solving social disparities 
in their communities. Dr Lance O'Sullivan, a highly regarded medical practitioner, is also a social innovator who has brought his philosophical perspective and passion for social justice to his medical practice in an isolated, rural community in the Far North of Aotearoa New Zealand.

The case of Dr O'Sullivan and iMOKO illustrates how a focus on social problems and an analysis of available innovations can deliver solutions to disadvantaged communities that change power dynamics, ameliorate poverty and deliver meaningful change. This individual has created a business that reflects his cultural identity, an expression of his cultural capital. Further, the social milieu from which Lance O'Sullivan and his organisation have emerged is an example of strong and vibrant social capital, whether from his upbringing by a resilient mother, his community in the Far North, Catholic beliefs, or passion for egalitarianism and emancipation. O'Sullivan provides both a model and a challenge to other health practitioners, policymakers, and health funders, but he does so within a context of innovative thinking, drawing on technological, cultural, social, and professional strengths.

Notwithstanding the well-documented limitations of a single case, we argue this particular case provides useful empirical validation of Indigenous social innovation and social entrepreneurship, and elucidates the factors that underpin these entrepreneurs, and the outcomes for communities. It is from this analysis that we may contribute to a more robust conceptualisation of the contribution that Indigenous research and theory can bring to our understanding of Indigenous peoples and their drive for revitalisation and well-being.

\section{ACKNOWLEDGEMENT}

The authors acknowledge that this manuscript is an original work that has not been submitted to nor published anywhere else. All authors have read and approved the paper.

\section{References}

Alvord, S. H., Brown, L. D., \& Letts, C. W. (2004). Social entrepreneurship and societal transformation: An exploratory study. The Journal of Applied Behavioral Science, 40(3), 260-282.

Anderson, R. B., Honig, B., \& Peredo, A. (2006). Communities in the global economy: Where social and Indigenous entrepreneurship meet. In C. Steyaert \& D. Hjorth (Eds.), Entrepreneurship as social change: A third new movement in entrepreneurship book (pp. 56-78). Cheltenham, UK: Edward Elgar.

Aramburu, N., \& Saenz, J. (2011). Structural capital, innovation capability, and size-effect: An empirical study. Journal of Management \& Education, 17, 307-325.

Ayob, N., Teasdale, S., \& Fagan, K. (2016). How social innovation 'came to be': Tracing the evolution of a contested concept. Journal of Social Policy, 45(4), 1-19.

Bishop, R. (1996). Collaborative research stories whakawhanaungatanga. Palmerston North, New Zealand: The Dunmore Press Ltd.

Bishop, R. (2008). Freeing ourselves from neocolonial domination in research. In N. K. Denzin \& Y. S. Lincoln (Eds.), The landscape of qualitative research (3rd ed., pp. 199-219). Thousand Oaks, CA: Sage.

Bowen, G. A. (2009). Document analysis as a qualitative research method. Qualitative Research Journal, 9(2), 27-40. https://doi.org/10.3316/QRJ0902027

Cahn, M. (2008). Indigenous entrepreneurship, culture and microenterprise in the Pacific Islands: Case studies from Samoa. Entrepreneurship \& Regional Development: An International Journal, 20(1), 1-18. https://doi.org/ $10.1080 / 08985620701552413$

Christensen, C. (2013). The innovator's dilemma: When new technologies cause great firms to fail. Boston, MA: Harvard Business Review Press.

Dana, L.-P., \& Anderson, R. (2007). A multidisciplinary theory of entrepreneurship as a function of cultural perceptions of opportunity. In L.-P., Dana \& R. Anderson (Eds.), International handbook of research on Indigenous entrepreneurship (pp. 3-8). Cheltenham, UK: Edward Elgar. 
Dyer, W. G., \& Wilkins, A. L. (1991). Better stories, not better constructs, to generate better theory: A rejoinder to Eisenhardt. The Academy of Management Review, 16(3), 613-619.

Espiner, G. (2014). Dr Lance O'Sullivan: New Zealander of the Year 2014. Retrieved June 8, 2017, from http://www. noted.co.nz/archive/listener-nz-2014/dr-lance-o-sullivan-new-zealander-of-the-year-2014/

Foley, D. (2004). Understanding Indigenous entrepreneurship: A case study analysis. Unpublished PhD thesis, University of Queensland, Brisbane, Australia.

Foley, D., \& O'Connor, A. J. (2013). Social capital and the networking practices of Indigenous entrepreneurs. Journal of Small Business Management, 51(2), 276-296.

Glaser, B. G., \& Strauss, A. L. (1967). The discovery of grounded theory: Strategies for qualitative research. Chicago, IL: Aldine Pub. Co.

Goodall, L. (2016). Disruptive thinking: Rocket fuel for Māori innovation. Retrieved June 8, 2017, from http:// sciblogs.co.nz/matau-taiao/2016/07/06/disruptive-thinking-Māori-innovation

Harris, H. (2001). Content analysis of secondary data: A study of courage in managerial decision making. Journal of Business Ethics, 34, 191-208.

Heil, D., \& Whittaker, L. (2007). An ontological foundation for strategic management research: The role of narrative. Research Methodology in Strategy and Management, 4, 369-397.

Heiskala, R. (2007). Social innovations: Structural and power perspectives. In T. J. Hamalainen \& R. Heiskala (Eds.), Social innovations, institutional change and economic performance (pp. 52-79). Cheltenham, UK: Edward Elgar.

Heiskala, R. (2015). Relating Mann's conception to CRESSI. A deliverable of the project: "Creating Economic Space for Social Innovation" (CrESSI). European Commission - 7th Framework Programme, Brussels: European Commission, DG Research and Innovation.

Hēnare, M. (2001). Tapu, mana, mauri, hau, wairua. A Māori philosophy of vitalism and cosmos. In J. Grim (Ed.), Indigenous traditions and ecology: The interbeing of cosmology and community (pp. 197-221). Cambridge: Harvard University Press for the Centre for the Study of World Religions.

Henry, E. (2012). Te Wairua Auaha: Emancipatory Māori entrepreneurship in screen production. Doctoral thesis, Auckland University of Technology, Auckland, New Zealand. Retrieved 1 September 2017 from http://hdl.handle. net/10292/4085

Henry, E., Dana, L-P., and Murphy, P. (2017). Telling their own stories: Māori entrepreneurship in the mainstream screen industry. Entrepreneurship \& Regional Development, pp 1-28. DOI: 10.1080/08985626.2017.1388445.

Henry, E., \& Pene, H. (2001). Kaupapa Māori research, locating Indigenous ontology, epistemology and methodology in the academy. Organization, 8(2), 234-242.

Henry, E., \& Wikaire, M. (2013). The brown book: Māori in screen production. Auckland, New Zealand: Ngā Aho Whakaari.

Hindle, K., \& Moroz, P. (2010). Indigenous entrepreneurship as a research field: Developing a definitional framework from the emerging canon. International Entrepreneurship Management Journal, 6, 357-385. https://doi.org/10.1007/ s11365-009-0111-x

Kaye, M. (1996). Myth-makers and story-tellers: How to unleash the power of myths, stories and metaphors to understand the past, envisage the future, and create lasting and positive cultural change in your organisation. Chatswood, NSW: Business \& Professional Publishing.

Light, I., \& Dana, L-P. (2013). Boundaries of social capital in entrepreneurship. Entrepreneurship Theory and Practice, 37(3), 603-624.

MacCallum, D., Moulaert, F., Hillier, J., \& Haddock, S. V. (Eds.) (2009). Social innovation and territorial development. Aldershot, UK: Ashgate.

Mann, M. (1986). The sources of social power: Volume 1, A history of power from the beginning to A.D. 1760. Cambridge: Cambridge University Press.

Mann, M. (2013). The sources of social power: Volume 4, Globalizations, 1945-2011. Cambridge: Cambridge University Press.

Mauss, M. (1954). The gift: The form and reason for exchange in archaic societies (translated by I. Cunnison). New York, London: Cohen \& West.

Mika, J. P. (2015). The role of publicly funded enterprise assistance in Māori entrepreneurship in Aotearoa New Zealand. A thesis submitted in partial fulfilment of the requirements for the degree of Doctor of Philosophy in Business, Massey University, Palmerston North, New Zealand.

Mika, J. P. (2016). What is Māori innovation: To snare the sun, and then some... Idealog. Retrieved June 12, 2017, from http://idealog.co.nz/venture/2016/06/what-Māori-innovation-snare-sun-and-then-some 
Ministry of Education (2017). Ministry funding deciles. Retrieved June 8, 2017, from https://parents.education.govt. $\mathrm{nz} /$ primary-school/schooling-in-nz/ministry-funding-deciles/

Moulaert, F. (2009). Social innovation: Institutionally embedded, territorially (re)produced. In D. MacCallum, F. Moulaert, J. Hillier, \& S. V. Haddock (Eds.), Social innovation and territorial development (pp. 11-23). London, New York: Ashgate.

Moulaert, F., MacCallum, D., Mehmood, A., Hamdouch, A., Hillier, J., \& Beinstein, B. (2010). Social innovation: Collective action, social learning and transdisciplinary research. Final report: Towards a handbook. KATARSIS 029044, pp. 1-220.

Mulgan, G., Tucker, S., Ali, R., \& Sanders, B. (2007). Social innovation: what it is, why it matters and how it can be accelerated. Oxford University: Skoll Centre for Social Innovation.

Newth, J., \& Woods, C. (2014). Resistance to social entrepreneurship: How context shapes innovation. Journal of Social Entrepreneurship, 5(2), 192-213.

Nicholls, A. (2017). Policy paper: How to facilitate the growth of different kinds of social innovation: The politics of social innovation. A deliverable of the project: "Creating Economic Space for Social Innovation" (CrESSI). European Commission - 7th Framework Programme, Brussels: European Commission, DG Research and Innovation.

Nicholls, A., \& Teasdale, S. (2017). Neoliberalism by stealth? Exploring continuity and change within the UK social enterprise policy paradigm. Policy \& Politics, 45(3), 323-341. https://doi.org/10.1332/030557316 X14775864546490

Nicholls, A., \& Ziegler, R. (2015). An extended social grid model for the study of marginalization processes and social innovation. A deliverable of the project: "Creating Economic Space for Social Innovation" (CrESSI). European Commission - 7th Framework Programme, Brussels: European Commission, DG Research and Innovation.

NZ Herald (2015). A new focus for medical trail-blazers. Retrieved June 8, 2017, from http://www.nzherald.co.nz/ lifestyle/news/article.cfm?c_id=6\&objectid $=11470943$

NZ Herald (2016). How Lance O'Sullivan turned his life around. Retrieved June 8, 2017, from www2.nzherald.co.nz/ northlandage/news/article.cfm?c_id $=1503402 \&$ objectid $=11591465$

O'Sullivan, L. (2015). The good doctor: Breaking the rules, making a difference. Auckland, New Zealand: Penguin.

O’Sullivan, L. (2017). Speech presented at District Court Judges conference in Auckland, Waiheke.

OECD (2000). LEED forum on social innovation. Retrieved from http://www.oecd.org/document/21/0,3746, en_2649_34417_44255253_1_1_1_1,00.html

Overall, J., Tapsell, P., \& Woods, C. (2010). Governance and Indigenous social entrepreneurship: When context counts. Social Enterprise Journal, I(2), 146-161.

Panelli, R., Gallagher, L., \& Kearns, R. (2006). Access to rural health services: Research as community action and policy critique. Social Science \& Medicine, 62, 1103-1114.

Patton, M. Q. (2002). Qualitative research \& evaluation methods. Thousand Oaks, CA: Sage.

Peredo, A. M., Anderson, R. B., Galbraith, C. S., Honig, B., \& Dana, L-P. (2004). Towards a theory of Indigenous entrepreneurship. International Journal of Entrepreneurship and Small Business, 1(1), 1-20.

Peredo, A. M., \& McLean, M. (2010). Indigenous development and the cultural captivity of entrepreneurship. Business \& Society, 52(4), 592-620.

Petrie, H. (2006). Chiefs of industry: Māori tribal enterprise in early colonial New Zealand. Auckland, New Zealand: Auckland University Press.

Pol, E., \& Ville, S. (2009). Social innovation: Buzz word or enduring term? The Journal of Socio-Economics, 38(6), 878-885.

Robin, A., Mills, C., Tuck, R., \& Lennon, D. (2013). The epidemiology of acute rheumatic fever in Northland. New Zealand Medical Journal, 126(1373), 46-52.

Scoop (2015). Kaitaia medical pioneer wins $\$ 30 \mathrm{k}$ business development grant. Retrieved June 8, 2017, from http:// www.scoop.co.nz/stories/BU1507/S00708/kaitaia-medical-pioneer-wins-30k-business-development-grant.htm

Sen, A. (1985). Commodities and capabilities. Amsterdam: North Holland.

Seuffert, N. (1997). Circumscribing knowledge in Aotearoa/New Zealand: Just epistemology. Yearbook of New Zealand Jurisprudence, 1, 97-125.

Silverman, D. (2006). Interpreting qualitative data: Methods for analyzing talk, text and interaction. Thousand Oaks, CA: Sage.

Smith, G. H. (1997). The development of kaupapa Māori: Theory and praxis. Unpublished PhD thesis, The University of Auckland, Auckland. 
Smith, L. T. (1998). Decolonizing methodologies: Research and indigenous peoples. New York/Dunedin: Zed Books/ University of Otago Press.

Spiller, C., Erakovic, L., Hēnare, M., \& Pio, E. (2010). Relational well-being and wealth: Māori businesses and an ethic of care. Journal of Business Ethics, 98(1), 153-169. https://doi.org/10.1007/s10551-010-0540-z

Spiller, C., Pio, E., Erakovic, L., \& Hēnare, M. (2011). Wise up: Creating organizational wisdom through an ethic of Kaitiakitanga. Journal of Business Ethics, 104(2), 223-235.

Spiller, C., \& Wolfgramm, R. (Eds.) (2015). Indigenous spiritualties at work: Transforming the spirit of business enterprise. Charlotte, NC: Information Age Publishing.

Tapsell, P., \& Woods, C. (2010). Social entrepreneurship and innovation: Self-organization in an Indigenous context. Entrepreneurship and Regional Development, 22(6), 535-556.

Throsby, D. (1999). Cultural capital. Journal of Cultural Economics, 23(1), 3-12.

von Jacobi, N., Edmiston, D., \& Ziegler, R. (2017). Tackling marginalisation through social innovation? Examining the EU social innovation policy agenda from a capabilities perspective. Journal of Human Development and Capabilities, 18(2), 148-162.

Wilson, C. (2012). New Zealand History. Ministry for Culture and Heritage. Retrieved December 20, 2012, from http://www.nzhistory.net.nz/media/photo/charles-wilson

Yin, R. (1994). Discovering the future of the case study method in evaluation research. Evaluation Practice, 15, 283-290.

Yin, R. (1984/2013). Case study research: Design and methods. Thousand Oaks, CA: Sage.

Yujuico, E. (2008). Connecting the dots in social entrepreneurship through the capabilities approach. Socio-Economic Review, 6(3), 493-513. 